Wright State University

CORE Scholar

$11-1-2002$

\title{
Microcathodoluminescence and Electron Beam Induced Current Observation of Dislocations in Freestanding Thick n-GaN Sample Grown by Hydride Vapor Phase Epitaxy
}

\author{
A. Y. Polyakov \\ A. V. Govorkov \\ N. B. Smirnov \\ Z-Q. Fang \\ David C. Look \\ Wright State University - Main Campus, david.look@wright.edu
}

See next page for additional authors

Follow this and additional works at: https://corescholar.libraries.wright.edu/physics

Part of the Physics Commons

\author{
Repository Citation \\ Polyakov, A. Y., Govorkov, A. V., Smirnov, N. B., Fang, Z., Look, D. C., Park, S. S., \& Han, J. H. (2002). \\ Microcathodoluminescence and Electron Beam Induced Current Observation of Dislocations in \\ Freestanding Thick n-GaN Sample Grown by Hydride Vapor Phase Epitaxy. Journal of Applied Physics, 92 \\ (9), 5238-5240. \\ https://corescholar.libraries.wright.edu/physics/150
}

This Article is brought to you for free and open access by the Physics at CORE Scholar. It has been accepted for inclusion in Physics Faculty Publications by an authorized administrator of CORE Scholar. For more information, please contact library-corescholar@wright.edu. 


\section{Authors}

A. Y. Polyakov, A. V. Govorkov, N. B. Smirnov, Z-Q. Fang, David C. Look, Seong-Ju S. Park, and J. H. Han 


\title{
Microcathodoluminescence and electron beam induced current observation of dislocations in freestanding thick $n$-GaN sample grown by hydride vapor phase epitaxy
}

\author{
A. Y. Polyakov, A. V. Govorkov, and N. B. Smirnov \\ Institute of Rare Metals, Moscow, 109017, B. Tolmachevbsky, 5, Russia \\ Z-Q. Fang a) and D. C. Look \\ Semiconductor Research Center, Wright State University, Dayton, Ohio 45435 \\ S. S. Park and J. H. Han \\ Samsung Advanced Institute of Technology, P.O. Box 111, Suwon, Korea, 440-600
}

(Received 20 June 2002; accepted 2 August 2002)

\begin{abstract}
Microcathodolumunescence (MCL) spectra measurements, MCL and electron beam induced current (EBIC) imaging of the freestanding $n$-GaN samples grown by hydride vapor phase epitaxy were made. Dark-spot defects in plan-view EBIC and MCL images and dark line defects in MCL images taken on the cleaved surface of the samples could be associated with dislocations. MCL spectra measurements in the vicinity of dislocations and in the matrix do not reveal specific luminescence bands that could be attributed to dislocations but rather suggest that dislocation regions have higher density of deep nonradiative traps. (C) 2002 American Institute of Physics.
\end{abstract}

[DOI: $10.1063 / 1.1511822]$

\section{INTRODUCTION}

There is growing evidence that dislocations can act as efficient recombination centers in $n$-GaN strongly influencing the recombination characteristics ${ }^{1}$ and the electrical properties. ${ }^{2}$ In some cases the dislocations could be directly related to dark-spot defects in microcathodoluminescence (MCL) or electron beam induced current (EBIC) images (see, e.g., Ref. 3). Also, recently tunneling electron microscope studies showed that the luminescence intensity near a dislocation core was substantially lower than in the surrounding material. ${ }^{4}$ Models describing the influence of dislocations on the diffusion lengths of minority carriers and on the apparent electron conductivity and mobility have been developed, e.g., in Refs. 1 and 2 and have been shown to be in reasonably good agreement with experiment. However, in ordinary cases direct studies of individual dislocations in GaN films are made very difficult because of their very high density, on the order of $10^{9}-10^{10} \mathrm{~cm}^{-2}$. This situation is greatly alleviated in thick $\mathrm{GaN}$ films grown by hydride vapor phase epitaxy (HVPE) and having the dislocation density sometimes as low as below $10^{8} \mathrm{~cm}^{-2} .{ }^{5}$ Recently researchers from Samsung Electronics have demonstrated thick freestanding $n$-GaN films with a dislocation density near the upper $(\mathrm{Ga})$ surface sometimes below $10^{6} \mathrm{~cm}^{-2}{ }^{6}$ These films also show excellent electrical properties, with a $300 \mathrm{~K}$ electron concentration of about $6 \times 10^{15} \mathrm{~cm}^{-3}$, and a $300 \mathrm{~K} \mathrm{mo-}$ bility as high as $1310 \mathrm{~cm}^{2} / \mathrm{V} \mathrm{s}{ }^{7}$ Thus such samples would present perfect objects for studies, including spectroscopic studies, of the recombination properties of individual dislocations using EBIC and MCL techniques. This was the objective of the current article.

\footnotetext{
a)Electronic mail: zhaoqiang.fang.@wright.edu
}

\section{EXPERIMENT}

The sample studied in this article was grown at Samsung Electronics by hydride vapor phase epitaxy and detached from the sapphire substrate by a laser lift-off process. ${ }^{8}$ After grinding to achieve flat surfaces, both the upper $(\mathrm{Ga})$ face and the lower $(\mathrm{N})$ face of the sample were subjected to reactive ion etching known to leave behind a surface damaged layer, about $0.5 \mu \mathrm{m}$ deep, having a reduced concentration of electrons and a high density of deep traps (see, e.g., Ref. 9). The total sample thickness after the surface preparation was about $180 \mu \mathrm{m}$. The dislocation density was not measured on this particular sample but on a similarly grown sample studied in Ref. 6 the dislocation density measured by transmission electron microscopy on the $\mathrm{Ga}$ face was about $10^{6} \mathrm{~cm}^{-2}$. Hall-effect measurements on an adjacent piece of material gave a $300 \mathrm{~K}$ mobility of $1270 \mathrm{~cm}^{2} / \mathrm{V} \mathrm{s}$, and a carrier concentration of $1.07 \times 10^{16} \mathrm{~cm}^{-3}$. The electron concentration deduced from capacitance-voltage profiling on the current sample was about $3-4 \times 10^{15} \mathrm{~cm}^{-3}$ in the damaged region near the surface and about $5-8 \times 10^{15} \mathrm{~cm}^{-3}$ in the bulk of the film.

The measurements involved imaging of the sample in a scanning electron microscope using room-temperature EBIC and low-temperature $(90 \mathrm{~K})$ monochromatic MCL modes and also $90 \mathrm{~K} \mathrm{MCL}$ spectra measurements in selected portions of the sample. For EBIC measurements, Au Schottky diodes with an area of $0.75 \mathrm{~mm} \times 0.75 \mathrm{~mm}$ were deposited by vacuum evaporation through a shadow mask. The properties of the Schottky diodes will be described in a separate article. ${ }^{10}$ The experimental setups are described in detail, e.g., in Ref. 11. 


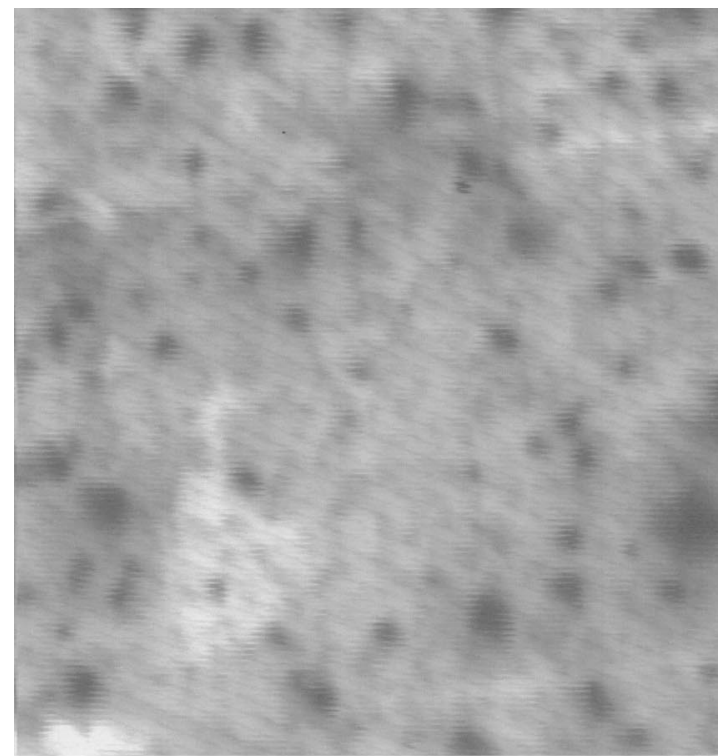

(a)

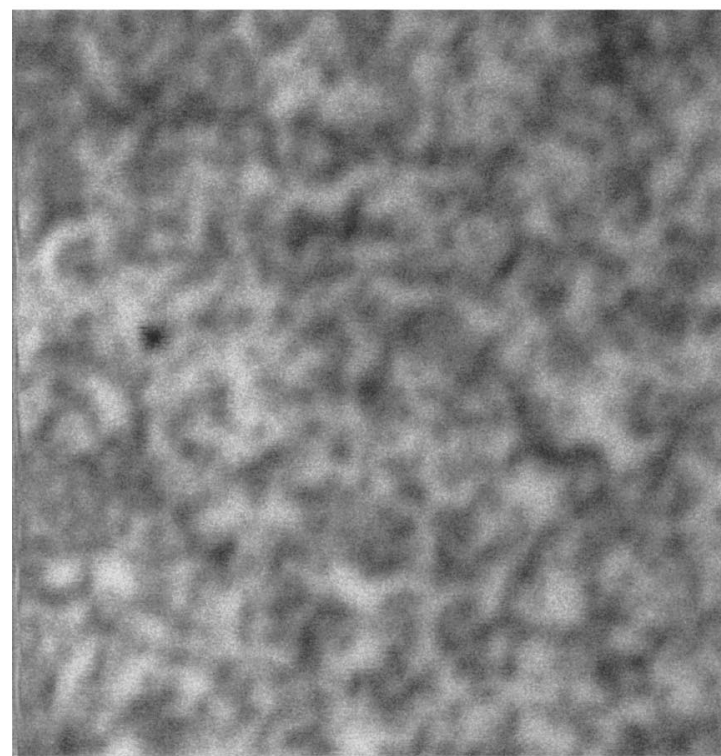

(b)

FIG. 1. (a) EBIC image of the Ga surface of the freestanding $n$-GaN sample; measurements taken at zero bias, with the electron beam accelerating voltage at $25 \mathrm{kV}$; the full scale of the figure is $120 \mu \mathrm{m} \times 120 \mu \mathrm{m}$; (b) MCL image of the Ga surface of the same sample taken near the Schottky diode; measurements at $90 \mathrm{~K}$, in the $3.45 \mathrm{eV}$ MCL band, with accelerating voltage of $25 \mathrm{kV}$; the full scale of the figure is $120 \mu \mathrm{m} \times 120 \mu \mathrm{m}$.

\section{RESULTS AND DISCUSSION}

In Fig. 1(a) we present the EBIC image of the Ga surface of the freestanding GaN sample. The most interesting detail of the image is the presence of small dark spots with the density on the order of $10^{6} \mathrm{~cm}^{-2}$, i.e., close to the expected dislocation density in this sample. MCL imaging of the sample at a photon energy of $3.45 \mathrm{eV}$ (above band gap at 300 $\mathrm{K})$ also showed the presence of dark spots but their density was more than an order of magnitude higher than that found in the EBIC image [see Fig. 1(b), the image was taken near the Schottky diode]. The results are consistently observed on various Schottky diodes and do not stem from nonuniform distribution of the density of dark-spot defects. Moreover,

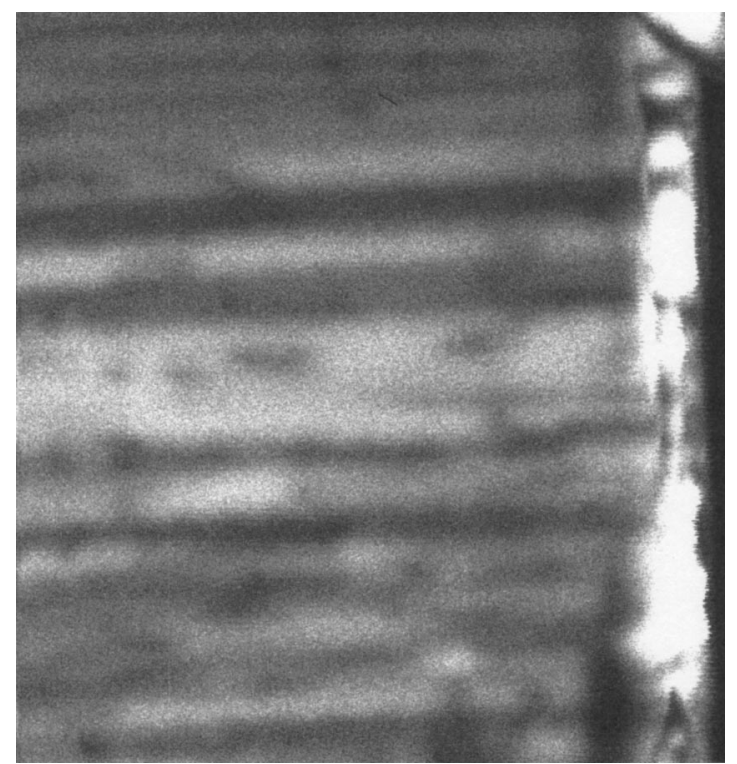

FIG. 2. Cross-sectional MCL image taken near the Ga surface at $90 \mathrm{~K}$, in the $3.45 \mathrm{eV}$ MCL band, with accelerating voltage of $15 \mathrm{kV}$; the full scale of the figure is $120 \mu \mathrm{m} \times 120 \mu \mathrm{m}$.

when imaging of the sample in the MCL mode was performed through the Au metal of the Schottky barrier using a high beam current for excitation, the EBIC and the MCL images still differed as shown in Fig. 1. If we suspect that the origin of the dark spots in the EBIC image is the enhanced recombination near dislocations the difference in the apparent densities of dark spots in the EBIC and MCL images could be attributed to the presence of the damaged region near the surface and to the fact that the impact of this damaged region could be less pronounced in the EBIC mode because the space charge region thickness with full collection of electrons is about $0.4-0.5 \mathrm{~mm}$ even at zero bias and covers the good part of the damaged region thickness. If that were the case one would expect that on the cleaved surface of the sample the dislocations will still be visible as dark lines but their density would be in better conformity with the density deduced from the EBIC image. Figure 2 presents the $90 \mathrm{~K} 3.45 \mathrm{eV}$ MCL image of the cleaved surface near the Ga face. A set of straight dark lines with an average separation between 5 and $10 \mu \mathrm{m}$ can be clearly seen. The density of these defects is much closer to the density of dark spots in EBIC and it seems reasonable to attribute these dark lines to the threading dislocations around which the MCL intensity is greatly reduced. It was interesting to see if any specific bands in MCL would correlate with the distribution of dislocations. In Fig. 3 we present the $90 \mathrm{~K} \mathrm{MCL}$ spectra taken on the cleaved surface near the dark line and away from it on the bright area. It can be seen that on the dark line the intensity of all bands: the $I 2$ donor bound exciton band at $3.45 \mathrm{eV}$, the $3.4 \mathrm{eV}$ unidentified defect band, the donor-acceptor pairs series in the 3.1-3.3 eV range, and the green-yellow defect luminescence band at $2.2-2.5 \mathrm{eV}$ are substantially lower in the vicinity of dislocations. This result suggests that the contrast observed in MCL and EBIC images and possibly related to dislocations is due to the increased density of nonradiative recombination centers near dislocations rather than to the 


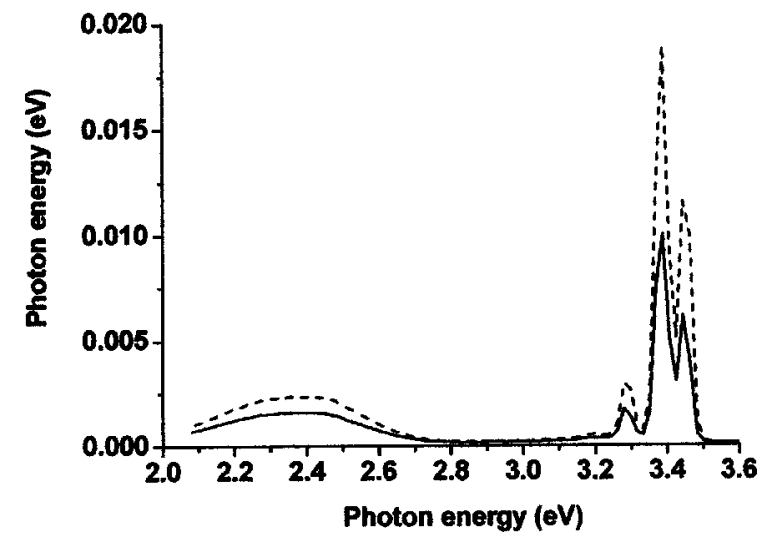

FIG. 3. MCL spectra taken at $90 \mathrm{~K}$ on the cleaved surface near the dark-line defects (solid line) and in the matrix (dashed line) [measurements were performed with low excitation intensity to make the contribution of the defect bands more pronounced (see Ref. 13)].

dominance of some dislocations related MCL band. It would be very interesting to perform local measurements of the densities of deep traps near dislocations using the variant of deep levels transient spectroscopy with electron beam excitation. ${ }^{12}$ This will be the next project to be carried out for such samples. The main obstacle here will be to get rid of the damaged region, e.g., by photoelectrochemical etching of the sample (scanning deep trap measurements on the cleaved surface will be technically rather difficult to carry out).

\section{CONCLUSIONS}

We have demonstrated the presence of dark-spot defects in the plan-view EBIC images and of the dark-line defects on the cross-sectional band edge MCL images taken on the Ga side of the freestanding HVPE grown $n$-GaN sample. The density of these dark-line defects is compatible with the expected dislocation density of some $10^{6} \mathrm{~cm}^{-2}$ near this surface as anticipated based on earlier transmission electron microscope measurements on similarly grown samples. MCL spectra measurements show that the intensity of all MCL bands is measurably lower in the vicinity of dark-line defects which suggests that these regions have a high concentration of nonradiative recombination centers. The density of darkspot defects in plan-view MCL images is much higher than that in the EBIC images and in the cross-sectional MCL images which we attribute to the impact of the surface damaged layer about $0.5 \mu \mathrm{m}$ thick whose presence has been demonstrated by independent capacitance-voltage profiling and deep level spectroscopy measurements to be reported elsewhere.

\section{ACKNOWLEDGMENTS}

The work at IRM was supported in part by a grant from the Russian Foundation for Basic Research (RFBR Grant No. 01-02-17230). The work of D.C.L. and Z.Q.F. was supported under AFOSR Grant No. F49620-00-1-0347. The authors would like to thank E. F. Astakhova for preparing the Au Schottky diodes used in this article.

${ }^{1}$ L. Chernyak, A. Osinsky, G. Nootz, A. Schulte, J. Jasinski, M. Benamara, Z. Liliental-Weber, D. C. Look, and R. J. Molnar, Appl. Phys. Lett. 77, 2695 (2000).

${ }^{2}$ D. C. Look and J. R. Sizelove, Phys. Rev. Lett. 82, 1237 (1999).

${ }^{3}$ S. J. Rosner, E. C. Carr, M. J. Ludowise, G. Girolami, and H. I. Erikson, Appl. Phys. Lett. 70, 420 (1997).

${ }^{4}$ S. Evoy, H. G. Craighead, S. Keller, U. K. Mishra, and S. P. DenBaars, J. Vac. Sci. Technol. B 17, 29 (1999).

${ }^{5}$ Z.-Q. Fang, D. C. Look, J. Jasinski, M. Benamara, Z. Liliental-Weber, and R. J. Molnar, Appl. Phys. Lett. 78, 332 (2001).

${ }^{6}$ J. Jasinski, W. Swider, Z. Liliental-Weber, P. Visconti, K. M. Jones, M. A. Reshchikov, F. Yun, H. Morkoç, S. S. Park, and K. Y. Lee, Appl. Phys. Lett. 78, 2297 (2001).

${ }^{7}$ D. C. Look and J. R. Sizelove (unpublished); Appl. Phys. Lett. 79, 1133 (2001).

${ }^{8}$ M. K. Kelly, R. P. Vaudo, V. M. Phanse, L. Gorgens, O. Ambacher, and M. Stutzmann, Jpn. J. Appl. Phys., Part 2 38, L217 (1999).

${ }^{9}$ D. C. Look and Z.-Q. Fang, Appl. Phys. Lett. 79, 84 (2001).

${ }^{10}$ A. Y. Polyakov, A. V. Govorkov, N. B. Smirnov, Z.-Q. Fang, D. C. Look, S. S. Park, and J. H. Han J. Appl. Phys. 92, 5241 (2002).

${ }^{11}$ A. Y. Polyakov, A. V. Govorkov, N. B. Smirnov, M. G. Mil'vidskii, J. M. Redwing, M. Shin, M. Skowronski, and D. W. Greve, Solid-State Electron. 42, 637 (1998).

${ }^{12} \mathrm{~K}$. Ikuta, N. Inoue, and K. Wada, in Semi-Insulating III-V Materials, edited by H. Kukimoto and S. Miyazawa (North-Holland, Amsterdam, 1986), pp. 427-432.

${ }^{13}$ A. Y. Polyakov, in GaN and Related Materials II, edited by S. J. Pearton (Gordon and Breach, the Netherlands, 2000), p. 173. 